\title{
Graphite Exfoliation by an Alternative Mechano-Chemical Process Using Sulfur as Exfoliating Agent
}

\author{
G. Tarango-Rivero ${ }^{1}$, C.G. Garay-Reyes ${ }^{1}$, I. Estrada-Guel ${ }^{1 *}$ and R. Martínez-Sánchez ${ }^{1}$. \\ 1. Centro de Investigación en Materiales Avanzados (CIMAV). Laboratorio Nacional de Nanotecnología \\ Miguel de Cervantes No. 120, 31136, Chihuahua, Chih., México. \\ *Corresponding author: ivanovich.estrada@cimav.edu.mx
}

Exfoliated and expanded graphite (EG) are functional carbon-based materials with high porosity, flexibility and excellent thermal/chemical stability. They can be widely used in some fields such as: sewage treatment, gasket manufacturing, fire-resistant composite preparation, etc. [1]. Both are obtained through chemical oxidation or electrochemical method of graphite. However, the preparation involves too many steps and product washing consumes a lot of water and large amounts of energy during the thermal expansion step carried out at high temperature [2]. Due to the above, it is important to develop a simple and ecological route to synthesize EGs to use them for ecologic issues such as promissory candidates for pollutants reduction [3], etc. It is well known that mechanical milling is a simple route to prepare a wide variety of material with improved properties which does not generate wastewater.

The present work describes an alternative route based on a solid-state exfoliation of natural graphite based on mechanical milling and a selective lixiviation process. Graphite exfoliation was carried out following a mechanochemical method using pure graphite (Gr) flakes and sulphur (S) powder used as exfoliating agent. Eight grams of an equiatomic mixture of Gr-S were processed in a Spex $8000 \mathrm{M}$ high-energy mill using a ball to powder mass ratio of 5:1 for $4 \mathrm{~h}$. After milling, a lixiviation process was carried out using pure carbon disulphide $\left(\mathrm{CS}_{2}\right)$ as a selective solvent for sulphur (34.8 $\mathrm{g}$ of sulphur are dissolved in $100 \mathrm{~g}$ $\mathrm{CS}_{2}$ at $25^{\circ} \mathrm{C}$, whereas graphite is practically insoluble). The milled powders were refluxed in a Soxhlet extractor device with $\mathrm{CS}_{2}$ for $20 \mathrm{~h}$, after extraction the solids were dried at $70^{\circ} \mathrm{C}$ for $1 \mathrm{~h}$. Morphology and elemental distribution of samples was done through a SEM-JSM-7201F microscope.

Fig. 1 shows SEM-EDS mapping (100X) of milled Gr-S samples where the bright green areas correspond to high $\mathrm{S}$ concentration regions (0h). After $4 \mathrm{~h}$ of milling (4h), S was homogeneously dispersed in graphite, resulting in a uniform distribution. Fig. 2 displays the composition of samples before and after the extraction process. It can be observed the evident concentration reduction of $\mathrm{S}$ after the lixiviation treatment. After processing, $\mathrm{CS}_{2}$ was distillated and pure sulphur was isolated, both chemical can be recycled for upcoming experimental. Fig. 3 exhibits some SEM micrographs of isolated graphite particles after processing ( 5 and $20 \mathrm{KX}$ ). It is evident the reduction of particle size and an increased level of defoliation reached with this process (in form of a huge number of isolated graphite layers and exposed surface).

\section{References:}

[1] L. Zhongping et al., Ceramics International 44 (2018), p. 16256.

[2] T.L. Ruijun Zhang et al., Carbon 119 (2017), p. 544.

[3] Z. Hu et al., Journal of Cleaner Production 209 (2019), p. 1216. 

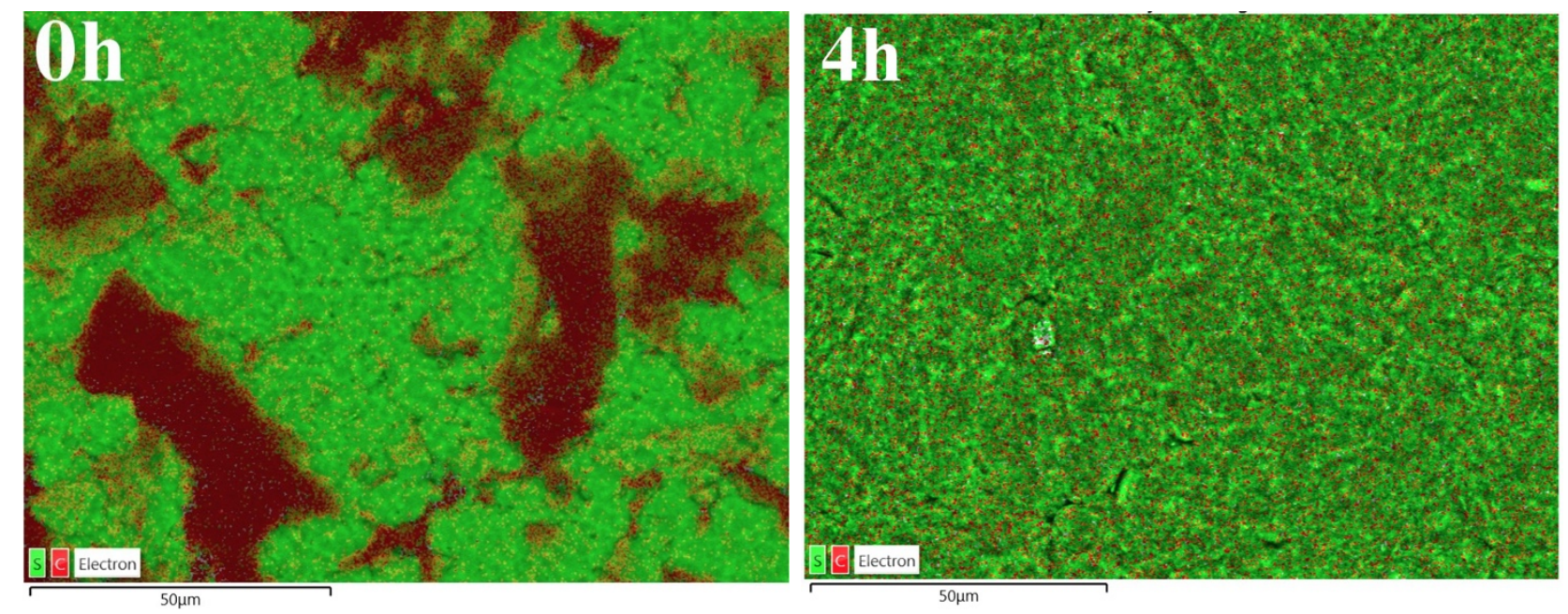

Figure 1. SEM mapping of un milled and $4 \mathrm{~h}$ milled samples showing the distributions of $\mathrm{S}$ and $\mathrm{C}$ components.
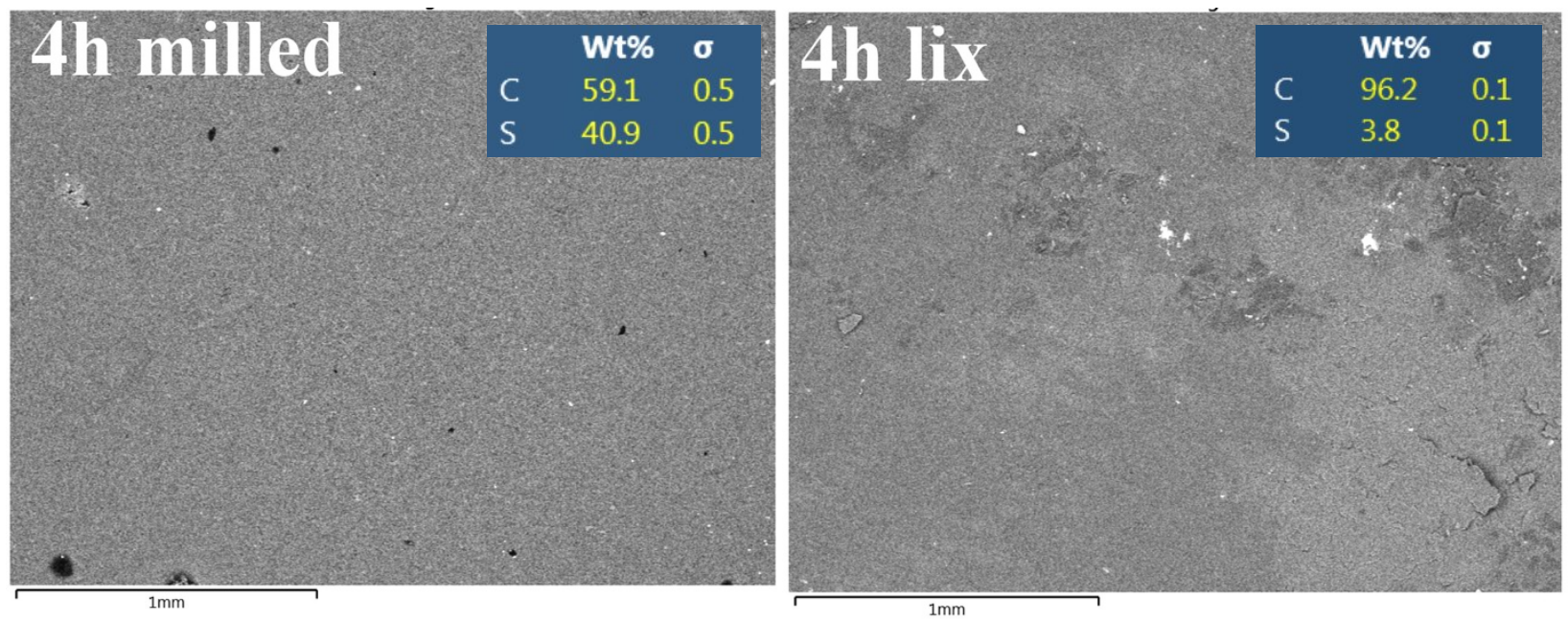

Figure 2. Low magnification SEM micrographs and EDS analyses of milled and extracted samples.
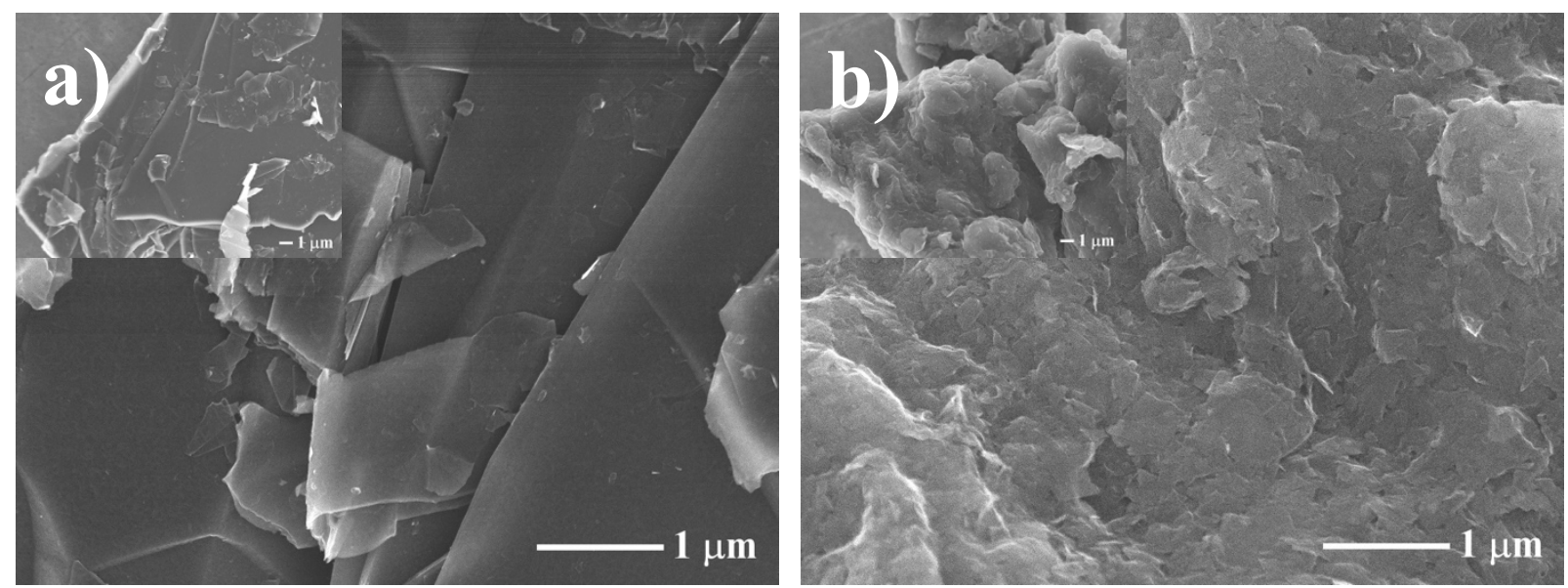

Figure 3. SEM micrographs of un milled (a) and 4h-extracted samples (b). 